\title{
The Impact of Fiqih Ibadah Materials on Amaliyah of Vocational High School Students
}

\author{
Eka Satriani $^{1 凶}$, Ahmad Putra $^{2}$ \\ Pendidikan Agama Islam, Universitas Negeri Padang, Indonesia ${ }^{1}$ \\ Bimbingan Konseling, Universitas Islam Negeri Sunan Kalijaga Yogyakarta, Indonesia ${ }^{2}$ \\ Email: ekasatriani89551@gmail.com¹, pratamaahmad954@gmail.com² \\ DOI: $10.31958 /$ jies.v1i2.3431
}

\begin{tabular}{ll}
\hline Article info & \multicolumn{1}{c}{ Abstract } \\
\hline & This study aims to determine the impact of fiqh ibadah (worship fiqh) material on \\
ArticleHistory & the amaliyah (worship practice) of the 287 XII grade students at SMKN 1 Kinali, \\
Recieved: & during the Covid 19 pandemic, because globally a third of the earth is experiencing \\
26/05/2021 & the disaster. This research was conducted using a qualitative method with a case \\
Accepted: & study design. All data were taken using in-depth interviews to fifteen informants \\
$17 / 11 / 2021$ & who were selected using purposive sampling technique. The researcher also took \\
Published: & data through documentation and observation. All data were then analyzed by \\
$30 / 11 / 2021$ & thematic and document analysis. Overall the results show that there are five kinds \\
& of mahdhah and ghairu mahdhah worship carried out by SMK students as routine \\
$\square$ & activities such as praying, fasting, giving alms, caring for fellow humans, and \\
Correspondingauthor & improving religious understanding.
\end{tabular}

Keywords: Learning, Fiqh of Worship, Student Amaliyah

\begin{abstract}
Abstrak
Penelitian ini bertujuan untuk mengetahui bagaimana dampak materi fiqh ibadah terhadap amaliyah peserta didik kelas XII di SMKN 1 Kinali yang berjumlah 287 orang pada masa pandemi atau covid 19 karena secara global sepertiga bumi mengalami bencana. Penelitian ini dilakukan menggunakan metode kualitatif dengan pendekatan studi kasus. Seluruh data diambil menggunakan wawancara mendalam kepada lima belas orang informan yang dipilih menggunakan teknik porposive sampling. Penulis juga mengambil data melalui dokumentasi, wawancara dan observasi. Seluruh data kemudian dianalisis dengan cara tematik dan analisis dokumen. Secara keseluruhan hasil penelitian menunjukkan terdapat lima bagian ibadah mahdhah dan ghairu mahdhah yang dijalankan oleh siswa SMK yang sudah menjadi rutinitas seperti sholat, dan berpuasa yang menjadi kewajiban dalam beragama Islam, membiasakan bersedekah, peduli terhadap sesama manusia, pemahaman ilmu agama selalu ditambah.
\end{abstract}

Kata Kunci: Pembelajaran, Fiqih Ibadah, Amaliyah Siswa, SMK

JIES islicensedunder a CreativeCommonsAtribution-ShareAlike 4.0 Internasional Licence 


\section{PENDAHULUAN}

Pendidikan merupakan salah satu cara yang dapat meningkatkan kecerdasan anak bangsa dan mampu bersaing dengan dunia luar (Fatona, 2020). Dalam Undang-Undang RI No. 20 tahun 2003 tentang sistem Pendidikan Nasional pasal 1 ayat mengatakan "pendidikan nasional pada hakikatnya adalah usaha sadar dan terencana untuk mewujudkan suasana belajar dan proses pembelajaran agar peserta didik secara aktif mengembangkan potensi dirinya untuk memiliki kekuatan spritual keagamaan, pengendalian diri, kepribadian, kecerdasan, akhlak mulia serta keterampilan yang diperlukan dirinya, masyarakat, bangsa dan negara". Pendapat lain mengatakan bahwa pendidikan sendiri adalah proses untuk membentuk diri peserta didik agar bermanfaat di kehidupan bermasyarakat (Indy et al., 2019).

Permasalahan yang terjadi pada dunia pendidikan tidak hanya terletak pada guru dan siswa, melainkan juga pada masyarakat dan pemerintah, sehingga semua pihak memiliki kewajiban untuk meningkatkan kualitas pendidikan yang ada di Indonesia (Suryani, 2007). Masyarakat yang demokratis dapat terwujud jika pendidikan nasional seperti yang tercantum dalam UUD 1945 memang benar-benar dapat memberikan kesempatan setiap masyarakat untuk menduduki dunia pendidikan sesuai degan potensi yang dimilikinya. Hal ini merupakan sesuatu yang harus diperhatikan untuk menghadapi dunia modern yang ada pada saat sekarang ini (Sabri et al., 2020; Tilaar, 2003).

Pendidikan dapat meningkatkan kualitas kehidupan pada diri individu, sehingga individu tersebut dapat hidup dengan baik dan melangsungkan kehidupannya, selain itu dengan adanya pendidikan setiap individu akan menjadi seorang yang terdidik sehingga dapat berguna bagi nusa, bangsa dan negara (Alpian et al., 2019). Pendidikan ada tiga macam, yaitu pendidikan informal, pendidikan formal dan pendidikan nonformal. Pendidikan yang pertama kali di dapatkan oleh setiap individu adalah pendidikan informal atau pendidikan yang didapatkan dari keluarga kita, selanjutnya barulah pendidikan informal dan non formal (Karo-karo, 2019). Pendidikan informal sendiri merupakan pendidikan yang didapatkan oleh setiap individu melalui pengalaman yang ada dalam kehidupannya. Pendidikan informal akan berlansung sejak seseorang dilahirkan ke dunia sampai ia meninggalkan dunia ini. Oleh karena itulah, pendidikan informal sangat bergantung pada keluarga dan orang tua kita. Jika orang tua mengajarkan kepada seorang individu maka akan dipastikan individu itu juga akan berperilaku baik (Alpian et al., 2019).

Pendidikan telah memberikan kebebasan kepada pemerintah, daerah maupun sekolah untuk mengembil kebijakan yang dirasa bagus untuk meningkatkan kualitas pendidikan di daerah tersebut yang sesuai dengan potensi yang dimiliki oleh daerah dan stakeholder sekolah tersebut (Aziz, 2015). Disamping diakui sebagai keputusan politis, desentralisasi pendidikan juga merupakan kebijakan yang menyangkut pada banyak hal. Pendidikan sendiri tidak akan jauh dari proses belajar dan mengajar yang dilakukan oleh pendidik. Kegiatan belajar dan pembelajaran merupakan interaksi yang mempunyai sifat edukasi untuk mencapai tujuan dari pendidikan (Pane \& Dasopang, 2017). Belajar 
merupakan sistem atau kegiatan yang terdapat dalam proses pembelajaran, sedangkan pembelajaran itu sendiri mempunyai komponen-komponen yang saling berhubungan satu dengan yang lainnya, yaitu siswa, guru, materi, metode, media, evaluasi dan tujuan dari pembelajaran itu (Warmansyah \& Amalina, 2019). Komponen dari pembelajaran tersebut saling memiliki hubungan dan ketergantungan. Pembelajaran akan berantakan jika ada salah satu ko mponen yang tidak berjalan dengan baik, oleh karena itu agar pembelajaran dapat berjalan dengan baik maka komponennya pun harus disiapkan dengan baik (Pane \& Dasopang, 2017; Warmansyah, 2020).

Pembelajaran akan menghasilkan interaksi antara pendidik dengan peserta didik yang menghasilkan sebuah pengalaman pada masing-masing individu. Cara yang digunakan pendidik saat melaksanakan pembelajaran akan mempengaruhi setiap peserta didik. Banyak hal yang harus dipersiapkan dan disepakati oleh pendidik bersama dengan peserta didik agar proses pembelajaran dapat dicapai dengan maksimal dan tidak ada unsur keterpaksaan (Putra et al., 2017). Pendidikan memiliki peran yang sangat besar dalam meningkatkan Sumber Daya Manusia (SDM) yang handal dan dapat bersaing dengan negara lain secara sehat dan dengan kerjasama. Ilmu pendidika itu sendiri merupakan ilmu yang bersifat praktis karena ilmu tersebut dijukan untuk praktek lansung untuk mempengaruhi peserta didik kea rah yang benar (Suryapermana \& Imroatun, 2017).

Mendidik bukanlah kegiatan yang mudah untuk dilakukan dikarenakan mendidik akan mempengaruhi kehidupan pada seseorang dan mempengarui generasi yang akan memimpin negara ini (Hidayati \& Warmansyah, 2021). Oleh karena itu, pendidikan disebut sebagai tugas moral yang tidak mudah untuk dilakukan. Karena pendidikan sangat penting, dan mempengaruhi masa depan bangsa, maka pemerintah memberikan perhatian khusus kepada pendidikan yang dimulai dari tingkat dasar, menengah sampai pada tingkat perguruan tinggi sekalipun. Bentuk dari perhatian tersebut adalah dengan menyediakan alokasi anggaran, membuat kebijakan yang dapat meningkatkan kualitas pendidikan, dan yang paling penting adalah selalu memberikan usaha terbaik dalam meningkatkan kualitas pendidikan yang ada di Indonesia ini (Alpian et al., 2019).

Pendidikan merupakan bentuk tindakan yang diberikan oleh pendidik atau orang dewasa kepada seseorang agar anak didik atau seseorang tersebut dapat berfikir dengan matang dan lebih dewasa (Saihu, 2020). Dengan adanya pendidikan, seseorang dapat mengembangkan potensi yang dimilikinya sehingga ia mampu menghadapi perubahan yang terjadi pada zaman yang diakibatkan oleh kemajuan teknologi dan pengetahuan (Haryoko \& Jaya, 2017).

Zaman ini stimulus dapat di terima dari berbagai media baik itu secara visual, audio ataupun audio visual, karena pada saat ini dinamakan dengan zaman digital yang dapat mengakses apa saja yang bisa dijadikan sebagai stimulus kepada seorang anak didik (Purnama, 2018). Dalam kehidupannya anak tidak akan lepas dari sentuhan lansung dari orang dewasa sampai ia menginjak usia dewasa. Bagi seorang anak media sosial merupakan suatu permainan yang harus dijalani agar dapat menjalani kehidupan dengan 
interaktif, kolaboratif, cepat dan ekspresif. Dengan hal tersebut, pemerintah mengeluarkan kebijakan untuk melaksanakan pembelajaran dari rumah untuk memutus mata rantai penyebaran Covid-19 sehingga orang tua dan guru harus bekerjasama dan lebih kreatif lagi dalam memberikan pelajaran kepada anak menggunakan teknologi yang ada (Firdaus, 2020).

Pendidikan dalam agama yang berawal umumnya dapat di sekolah harus dialihkan dengan pendidikan agama transformatif kemudian mengakomodir dunia anakanak pada generasi digital native. Orang tua hari ini memiliki peran atau amanah terhadap mendidik anak-anak agar selalu menjaga Aqidah serta berakhlakul karimah. Dengan hal ini pemerintah memiliki kebijakan untuk melakukan baik kerja, ibadah, maupun belajar di rumah masing-masing pada masa pandemi sekarang ini, maksudnya dengan cara seperti ini dapat mengembalikan "khittah" atau peran orangtua dalam mendidik anak-anak agar taat beribadah kepada Allah SWT (Septiani \& Kejora, 2021).

Salah satu hal diatur dalam program pendidikan yaitu agama, Indonesia mayoritas beragama Islam. Pendidikan Islam terbagi menjadi tiga yaitu pertama, seorang pendidikan dengan sungguh-sungguh membangkitkan semangat peserta didik, diberikan contoh dengan nama lembaga, kegiatan dilembaga dan sumber yang digunakan proses pendidikan mengandung nilai nilai Islami. Kedua, memberikan perhatian baik serta mengutamakan program dilakukan lembaga pendidikan berlandaskan Islami. Ketiga, gabungan dari dua pengertian di atas selain nama, sumber, program yang diutamakan lembaga mengaplikasikan nilai nilai Islami (Khoiriyah et al., 2020).

Secara sederhana pendidikan agama Islam dapat dikatakan adalah pendidikan tidak dikatakan berhasil jika belum berpengaruh pada kehidupan peserta didik, dan sebaliknya pendidikan dikatakan berhasil jika melahirkan peserta didik mampu menunaikan ibadah pada Allah SWT (Purnamasari, 2017). Dari definisi tersebut dapat disederhanakan bahwa pendidikan agama Islam ialah suatu usaha dalam proses belajar di mana dalamnya memberikan pengetahuan dan membentuk sikap, kepribadian dan keterampilan peserta didik dalam mengamalkan ajaran agama atau ibadah sesuai dengan al-qur'an dan sunnah. Pada pembelajaran pendidikan agama Islam materi fiqih ibadah merupakan bagian dari mata pelajaran tersebut yang mengarahkan peserta didik agar lebih mengenal, memahami, menghayati, mengamalkan hukum Islam yang menjadi landasan kehidupan sehari hari. Mata pelajaran ini merupakan hal penting yang harus dipelajari seorang peserta didik beragama Islam tentang ibadah seperti shalat, thaharah, puasa, haji dan lain sebagainya yang mutlak sebagai bekal untuk mengharap keridhaan pada Allah SWT agar bahagia dunia dan akhirat (Amirudin, 2019).

Seorang peserta didik harus memiliki akhlak mulia pada Allah SWT. Dengan menjalankan perintah-Nya dan menjauhi larangannya karena peserta didik merupakan generasi penerus bangsa yang nantinya akan melanjutkan pembangunan bangsa. Untuk mendapatkan lulusan yang berkualitas peserta didik harus memiliki akhlak mulia, taat pada Allah SWT. dan Rasul-Nya, mampu mengamalkan ibadah mahdah, ghairu mahdah sehingga ke depan dapat memimpin bangsa menjadi lebih baik yang diharapkan dapat 
mengubah keadaan peserta didik menjadi lebih baik. Sesuai dengan yang ditulis oleh Abdul Rahman Saleh bahwa bangsa Indonesia telah berketetapan melalui proses pendidikan itulah setiap warga negara Indonesia dibina dan tingkatkan keimanan dan ketakwaannya terhadap Tuhan Yang Maha Esa (Shofiyah, 2018).

Pada era globalisasi seluruh aspek kehidupan menciptakan lingkungan kurang mendukung bagi perkembangan jiwa dan kepribadian peserta didik (Mualim \& Saputra, 2021). Karena sistem yang mendunia ekonomi, politik, budaya dan pendidikan atau pendidikan agama sudah mulai menurun hasilnya. Pendidik kurang mengutamakan karakter, kewajiban dan tujuan kita diciptakan di dunia peserta didik, tetapi mendahulukan kognitif, kepintaran pada teknologi dan hal terbaru berkembang yang diciptakan oleh orang non muslim (Inanna, 2018). Tempat atau wadah dilakukan proses pendidikan pada umumnya disebut sekolah. Pendidikan di sekolah belum sepenuhnya memenuhi kesempurnaan, di mana sekolah SMKN 1 Kinali yang memiliki visi menjadikan lembaga pendidikan pelatihan kejuruan bertaraf nasional dan berwawasan lingkungan yang menghasilkan tamatan beriman dan bertaqwa kepada Tuhan Yang Maha Esa, profesional, mampu berwirausaha, handal, siap pakai, terampil, dan siap berkompetensi. Peserta didik SMKN 1 Kinali kelas XII berjumlah 287, 148 orang lakilaki dan 139 orang perempuan yang telah mempelajari Pendidikan Agama Islam, (Data Sekolah SMKN 1 Kinali, 2020), dapat dilihat di bawah ini hasil wawancara peneliti.

Berdasarkan data yang diperoleh dapat dideskripsikan bahwa informan 1, masih kurang teratur dalam melaksanakan shalat, sudah mulai teratur dalam melaksanakan puasa dibulan Ramadhan, masih kurang terbiasa dalam memberikan sedekah, masih kurang peduli terhadap sesama manusia, masih kurang paham ilmu yang telah dipelajari dua tahun yang lalu; informan 2, sudah mulai teratur dalam melaksanakan shalat, sudah mulai teratur dalam melaksanakan puasa dibulan Ramadhan, sudah mulai terbiasa dalam memberikan sedekah, sudah mulai peduli terhadap sesama manusia, sudah mulai paham ilmu yang telah dipelajari dua tahun yang lalu; informan 3, masih kurang teratur dalam melaksanakan shalat, masih belum teratur dalam melaksanakan puasa dibulan Ramadhan, sudah mulai terbiasa dalam memberikan sedekah, masih kurang peduli terhadap sesama manusia, masih kurang paham ilmu yang telah dipelajari dua tahun yang lalu; informan 4, sudah mulai teratur dalam melaksanakan shalat, sudah mulai teratur dalam melaksanakan puasa dibulan Ramadhan, masih kurang terbiasa dalam memberikan sedekah, sudah mulai peduli terhadap sesama manusia, masih kurang paham ilmu yang telah dipelajari dua tahun yang lalu; informan 5, masih kurang teratur dalam melaksanakan shalat, masih belum teratur dalam melaksanakan puasa dibulan Ramadhan, sudah mulai terbiasa dalam memberikan sedekah, masih kurang peduli terhadap sesama manusia, masih kurang paham ilmu yang telah dipelajari dua tahun yang lalu.

Berdasarkan kajian penelitian dan permasalahan tersebut maka penelitian ini mengkaji tentang dampak pembelajaran materi fiqh ibadah terhadap amaliyah siswa Sekolah Menengah Kejuruan (SMK). 


\section{METODE PENELITIAN}

Penelitian ini menggunakan metode kualitatif, pendekatan ini bersifat deskriptif kemudian lebih dominan menggunakan analisis untuk mencari makna serta proses yang ditampilkan agar sesuai dengan fakta di lapangan, untuk menyelidiki, menemukan, menggambarkan, dan menjelaskan kualitas atau keistimewaan dari pengaruh sosial yang tidak dapat dijelaskan, diukur atau digambarkan melalui pendekatan kuantitatif (Zakariah et al., 2020). Terkait dengan penelitian ini akan dijadikan, sumber data kualitatif diambil dari lima belas informan melalui wawancara mendalam. Sumber data ini siswa yang sekolah di SMKN 1 Kinali kelas XII pada tahun 2020 berbagai macam jurusan.

Teknik pengumpulan data menggunakan observasi, wawancara, dan dokumentasi. Teknik analisis data meliputi reduksi data (data reduction), penyajian data (data display) serta penarikan kesimpulan dan verifikasi (conclusion drawing/ verivication).

\section{HASIL DAN PEMBAHASAN}

Berdasarkan hasil wawancara yang dilakukan lima belas orang informan, hasil analisis secara nyata mendapat lima dampak pembelajaran materi fiqih ibadah terhadap amaliyah peserta didik yaitu sudah mulai teratur dalam sholat; sudah mengikuti puasa Ramadhan; terbiasa dalam sedekah; peduli terhadap sesama; pemahaman terhadap ilmu agama. Agar lebih menarik, penulis akan deskripsikan kutipan hasil wawancara dengan informan berdasarkan dampak pembelajaran materi fiqih terhadap amaliyah siswa yang telah dijelaskan di atas. Adapun deskripsi wawancara yang akan penulis tampilkan adalah kutipan pernyataan singkat dari informan ketika wawancara dilakukan. Kutipan wawanacara tesebut walaupun disampaikan informan dalam redaksi yang berbeda beda, namun sebenarnya mempunyai tujuan dan maksud yang kurang lebih sama.

\section{Pengamalan Ibadah Sholat}

Dalam bahasa Arab sholat adalah doa' yang berati suatu ibadah yang yang dimulai dari takbir dan diakhiri dengan salam dengan ketentuan dan syarat tertentu yang sudah diatur dalam Islam. Menurut Sulaiman Rasjid, dalam Mubaligh sholat itu terdiri dari 17 rakaat yang berjumlah 5 waktu, yaitu sholat subuh, zuhur, ashar, magrib dan isya, hal ini merupakan perintah yang Allah berikan pada Nabi akhir zaman yakni Muhammad SAW yang diturunkan pada malam hari yang disebut peristiwa isra' dan mi'raj Nabi Muhammad SAW (Saleh \& Jamil, 2020). Dalam penelitian ini untuk mendapatkan informasi apakah Shalat sudah menjadi rutinitas siswa sebagai seorang muslim, maka penulis melakukan wawancara kepada lima belas orang informan yang sekolah di SMKN 1 Kinali. Berdasarkan hasil wawancara tersebut penulis menyimpulkan terdapat tujuh orang yang sudah mulai rutin dalam sholat. Agar terlihat lebih jelas dapat dilihat pada gambar 1 berikut: 


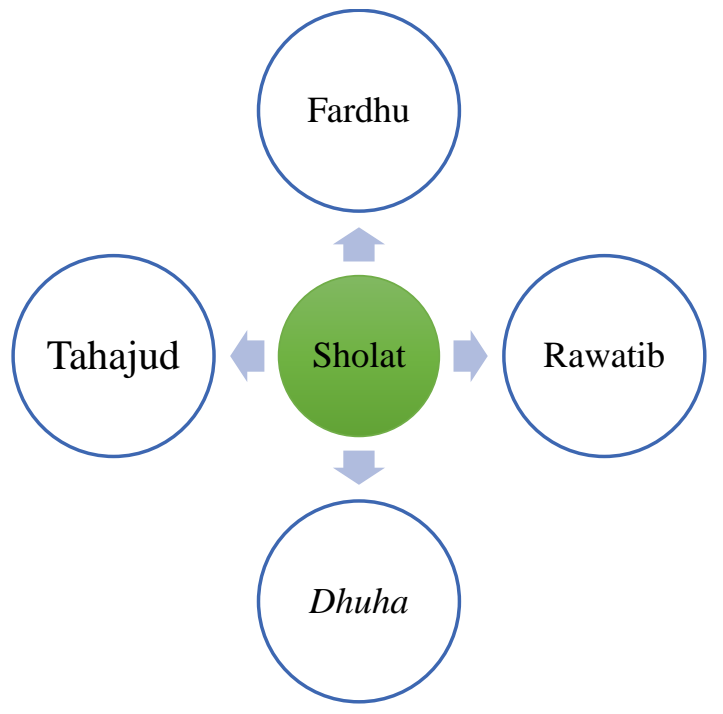

\section{Gambar 1: Deskripsi Sholat Menjadi Rutintitas Peserta Didik}

Penulis dapatkan dari informan dari sholat wajib dan sunah ketika wawancara langsung pada Kamis, 13 da 14 November 2020. Informasi tersebut disampaikan oleh informan dalam bahasa yang sedikit berbeda beda, namun mempunyai maksud yang kurang lebih sama. Berikut ini akan penulis tampilkan kutipan hasil wawancara penulis terkait tiga tema tersebut sebagaimana dilihat pada tabel 1,2, 3 dan 4 berikut:

Tabel 1: kutipan wawancara tema pertama dengan informan

\begin{tabular}{lll}
\hline Tema & Informan & \multicolumn{1}{c}{ Kutipan wawancara } \\
\hline Fardhu & Informan 2 & $\begin{array}{l}\text { Menurut saya Sholat Fardhu itu kewajiban } \\
\text { terhadap umat yang beragama Islam. }\end{array}$ \\
& Informan 11 & $\begin{array}{l}\text { Menurut saya Sholat Fardhu merupakan } \\
\text { dapat mencegah keji dan mungkar, agar } \\
\text { selamat dunia dan akhirat. }\end{array}$ \\
\hline
\end{tabular}

Tabel 2: kutipan wawancara tema kedua dengan informan

\begin{tabular}{lll}
\hline Tema & Informan & \multicolumn{2}{c}{ Kutipan wawancara } \\
\hline Rawatib & Informan 1 & Menurut saya sholat rawatib adalah untuk \\
& penyempurna sholat fardhu. \\
& Informan 3 & $\begin{array}{l}\text { Menurut saya sholat rawatib adalah } \\
\text { dilakukan sebelum dan sebelum sholat } \\
\end{array}$ \\
& fardhu. \\
\hline
\end{tabular}

Tabel 3: kutipan wawancara tema ketiga dengan informan

\begin{tabular}{ccc}
\hline Tema & Informan & \multicolumn{1}{c}{ Kutipan wawancara } \\
\hline Dhuha & Informan 2 & $\begin{array}{l}\text { Menurut saya sholat dhuha adalah salah satu } \\
\text { cara mendekatkan rezeki. }\end{array}$
\end{tabular}


Informan 4 Menurut saya sholat dhuha adalah cara untuk menguatkan tulang kita.

Tabel 4: kutipan wawancara tema keempat dengan informan

\begin{tabular}{ccc}
\hline Tema & Informan & \multicolumn{1}{c}{ Kutipan wawancara } \\
\hline Tahajud & Informan 5 & $\begin{array}{l}\text { Menurut saya sholat tahajud adalah untuk } \\
\text { mengabulkan doa kita. }\end{array}$
\end{tabular}

\section{Puasa}

Menurut Ibn Kasir puasa merupakan rukun Islam yang ke-tiga wajib kita lakukan dalam bentuk menahan diri dari makan dan minum serta hal membatalkan puasa, seperti dari lisan, perbuatan, hati yang perlu dijaga dari mulai terbit fajar hingga terbenamnya matahari (Rusdiana et al., 2020). Bagian ke 2 dari penelitian adalah seberapa banyak siswa yang telah menjadikan puasa sebagai kewajibannya, setelah diteliti lima belas informan terdapat 9 informan jadikan puasa kewajibannya.

Tabel 5: kutipan wawancara tema kedua dengan informan

\begin{tabular}{|c|c|c|}
\hline Tema & Informan & Kutipan wawancara \\
\hline \multirow[t]{3}{*}{ Puasa } & Informan 6 & $\begin{array}{l}\text { Menurut saya puasa adalah menahan haus } \\
\text { dan lapar serta hal yang membatlakan puasa } \\
\text { dari mulai terbit fajar hingga terbenamnya } \\
\text { matahari. }\end{array}$ \\
\hline & Informan 12 & $\begin{array}{l}\text { Menurut saya puasa merupakan suatu } \\
\text { amalan yang unik tidak diketahui banyak } \\
\text { orang lain. }\end{array}$ \\
\hline & Informan 13 & $\begin{array}{l}\text { Menurut saya puasa adalah menahan diri dari } \\
\text { hal hal yang membatalkan puasa. }\end{array}$ \\
\hline
\end{tabular}

\section{Peduli terhadap Sesama}

Peduli terhadap sesama merupakan suatu usaha dilakukan seseorang untuk peduli terhadap orang lain, lingkungan yang harus dimiliki agar saling mencintai sesama muslim dan diterapkan terhadap kehidupan sehari-hari (Purwanti, 2017). Bagian ke 3 dari penelitian adalah seberapa banyak siswa yang peduli terhadap sesama manusia agar terjadi rasa cinta terhadap sesama muslim yang bersaudara, setelah diteliti lima belas informan terdapat 5 informan jadikan zakat kewajibannya.

Tabel 6: kutipan wawancara tema ketiga dengan informan

\begin{tabular}{lcc}
\hline \multicolumn{1}{c}{ Tema } & Informan & Kutipan wawancara \\
\hline Peduli terhadap & Informan 6 & Menurut saya peduli terhadap sesama \\
sesama & & Karena muslim itu bersaudara.
\end{tabular}




$\begin{array}{ll}\text { Informan } 7 & \begin{array}{l}\text { Menurut saya peduli terhadap sesama adalah } \\ \text { bentuk akhlak seorang muslim. }\end{array} \\ \text { Informan } 8 & \begin{array}{l}\text { Menurut saya peduli terhadap sesama bentuk } \\ \text { rasa kemanusiaan. }\end{array}\end{array}$

\section{Sedekah}

Menurut Ghazali sedekah merupakan sebuah pemberian, harta berupa materi atau non materi seseorang secara ikhlas kepada orang lain atau berhak menerima untuk mengharap ridho Allah SWT (Wantoro, 2019). Bagian ke 4 dari penelitian adalah seberapa banyak siswa yang telah menjadikan sedekah sebagai kebiasaan untuk berbagi sesama manusia, setelah diteliti lima belas informan terdapat 6 informan jadikan zakat kewajibannya.

Tabel 7: kutipan wawancara tema keempat dengan informan

\begin{tabular}{|c|c|c|}
\hline Tema & Informan & Kutipan wawancara \\
\hline \multirow[t]{3}{*}{ Sedekah } & Informan 9 & $\begin{array}{l}\text { Menurut saya sedekah adalah bentuk rasa } \\
\text { peduli terhadap sesama. }\end{array}$ \\
\hline & Informan 10 & $\begin{array}{l}\text { Menurut saya sedekah merupakan ibadah } \\
\text { dengan memberikan harta pada orang lain } \\
\text { namun sebenarnya tidak mengurangi harta } \\
\text { kita. }\end{array}$ \\
\hline & Informan 12 & $\begin{array}{l}\text { Menurut saya sedekah adalah memberikan } \\
\text { harta dijalan Allah SWT. }\end{array}$ \\
\hline
\end{tabular}

\section{Pemahaman Ilmu Agama}

Menuntut Islam ilmu hukumnya wajib dipelajari apalagi ilmu agama karena, dengan ilmu agama dapat menunjukkan jalan seseorang untuk kebahagiaan dunia dan akhirat. Dan juga orang yang menuntut atau mencari ilmu akan didoa'kan oleh para malaikat yang disebutkan dalam sebuah hadist bahwa mereka akan mengepakkan sayapnya terhadap orang yang sedang mencari ilmu, karena mereka begitu meridhoinya (Manik, 2020). Dimensi pemahaman ilmu agama bagi peserta didik dengan menggunakan digital native atau secara tidak langsung dan juga mengharuskan generasi muslim memiliki kompetensi multi yang literasi. Pemahaman menggunakan seperti komputer atau program, yang dapat mengakses internet atau website, kemudian membaca teks atau tulisan dari screen, memahami informasi serta pengetahuan ilmu agama secara audio-visual, kemudian adab dalam dunia cyber dapat menjadi salah satu kesatuan pada generasi milenial atau $\mathrm{Z}$ dan kemudian memberikan dan mengajarkan ilmu agama melalui virtual atau Facebook, Instagram, Line, Whatsapp, Twitter, Telegram, dll (Kurdi, 2020). 
Bagian ke 5 dari penelitian adalah seberapa banyak siswa yang paham terhadap ilmu agama yang dipelajari dua tahun sebelumnya, setelah diteliti lima belas informan terdapat 2 informan jadikan zakat kewajibannya.

Tabel 8: kutipan wawancara tema kelima dengan informan

\begin{tabular}{ccl}
\hline Tema & Informan & \multicolumn{1}{c}{ Kutipan wawancara } \\
\hline Pemahaman & Informan 13 & $\begin{array}{l}\text { Menurut saya Pemahaman Ilmu Agama } \\
\text { adalah ilmu yang sangat penting dipelajari } \\
\text { Ilmu Agama }\end{array}$ \\
& agar selamat dunia dan akhirat. \\
& Informan 14 \\
& & Pemahaman Ilmu Agama adalah salah satu \\
& &
\end{tabular}

\section{KESIMPULAN}

Pendidikan agama Islam merupakan mata pelajaran yang wajib diikuti oleh seluruh pelajar pada setiap jenjang pendidikan di indonesia meskipun musibah melanda sepertiga umat didunia atau covid-19 dengan menggunakan media virtual. Dalam pembelajaran pendidikan agama Islam terdapat materi fiqih ibadah yang merupakan pelajaran sangat penting dipelajari oleh peserta didik untuk mengenal sholat, puasa, zakat, haji, zikir, sedekah, senyum atau ibadah mahdhah dan ghairu mahdhah lainya, agar selamat dunia dan akhirat. Di sekolah SMKN 1 Kinali peserta didik berjumlah 287, 148 orang laki-laki dan 139 orang perempuan yang telah mempelajari mata pelajaran pendidikan agama Islam.

\section{DAFTAR PUSTAKA}

Alpian, Y., Anggraeni, S. W., Wiharti, U., \& Soleha, N. M. (2019). Pentingnya Pendidikan Bagi Manusia. Jurna Buana Pengabdian, 1(1), 66-72. https://doi.org/10.36805/jurnalbuanapengabdian.v1i1.581

Amirudin, A. (2019). Memahami Otentisitas Konsep Tuhan; Kaca (Karunia Cahaya Allah): Jurnal Dialogis Ilmu Ushuluddin, 9(1), 65-86. https://doi.org/10.36781/kaca.v9i1.3008

Aziz, A. Z. (2015). Manajemen Berbasis Sekolah: Alternatif Peningkatan Mutu Pendidikan Madrasah. El-Tarbawi, 8(1), 69-92. https://doi.org/10.20885/tarbawi.vol8.iss1.art5

Fatona, N. (2020). Problematika Pendidikan Dalam Menyongsong Masa Depan Yang Gemilang. 'Adalah, 4(4). https://doi.org/10.15408/adalah.v4i4.16107

Firdaus, F. (2020). Implementasi dan Hambatan pada Pembelajaran Daring di Masa Pandemi Covid 19. Utile: Jurnal Kependidikan, 6(2), 220-225. https://doi.org/10.37150/jut.v6i2.1009

Haryoko, S., \& Jaya, H. (2017). Pengembangan Media Ajar Pada Mata Kuliah Pengantar Pendidikan Kejuruan. Jurnal Mekom (Media Komunikasi Pendidikan Kejuruan), 
4(2). https://doi.org/10.26858/mekom.v4i2.5134

Hidayati, W. R., \& Warmansyah, J. (2021). Aulad: Journal on Early Childhood Pendidikan Inklusi Sebagai Solusi dalam Pelayanan Pendidikan Untuk Anak Berkebutuhan Khusus. 4(3), 0-4. https://doi.org/10.31004/aulad.v4i3.161

Inanna, I. (2018). Peran Pendidikan Dalam Membangun Karakter Bangsa Yang Bermoral. Jekpend: Jurnal Ekonomi Dan Pendidikan, 1(1), 27-33.

Indy, R., Waani, F. J., \& Kandowangko, N. (2019). Peran Pendidikan Dalam Proses Perubahan Sosial Di Desa Tumaluntung Kecamatan Kauditan Kabupaten Minahasa Utara. Holistik, Journal Of Social and Culture, 12(4), 1-21.

Karo-karo, D. (2019). Membangun Karakter Anak Dengan Mensinergikan Pendidikan Informal Dengan Pendidikan Formal. Journal of Chemical Information and Modeling, 53(9), 1-13.

Khoiriyah, I. K., Roziqin, M. M., \& Ulfa, W. K. (2020). Pengembangan \{Kurikulum\} \{Pesantren\} dan \{Madrasah\}; \{Komponen\}, \{Aspek\} dan \{Pendekatan\}. Qudwatuna, 3(1), 25-46.

Kurdi, M. S. (2020). Doktrin Ajaran Islam untuk Generasi Muslim Di Masa Pandemi Info Artikel Keyword Abstrak. Jurnal Hawa, 2(2), 159-175.

Manik, W. (2020). kewajiban Menuntut Ilmu. Waraqat: Jurnal Ilmu-Ilmu Keislaman, 2(2), 17. https://doi.org/10.51590/waraqat.v2i2.63

Mualim, R., \& Saputra, M. F. (2021). Optimizing Online Learning during Covid 19 Pandemic in Junior High School. Journal of Islamic Education Students (JIES), 1(1), 19. https://doi.org/10.31958/jies.v1i1.3193

Pane, A., \& Dasopang, M. D. (2017). Belajar dan Pembelajaran. Fitrah:Jurnal Kajian Ilmu-Ilmu Keislaman, 3(2), 333. https://doi.org/10.24952/fitrah.v3i2.945

Purnama, S. (2018). Al Hikmah Proceedings on Islamic Early Childhood Education: Pengasuhan Digital untuk Anak Generasi Alpha Pengasuhan Digital untuk Anak Generasi Alpha. Al Hikmah Proceedings on Islamic Early Childhood Education, 1, 439-502.

Purnamasari, D. (2017). Pendidikan Karakter Berbasis Al-Quran. Islamic Counseling: Jurnal Bimbingan Konseling Islam, 1(1), 1. https://doi.org/10.29240/jbk.vli1.233

Purwanti, D. (2017). Pendidikan Karakter Peduli Lingkungan Dan Implementasinya. Dwija Cendekia: Jurnal Riset Pedagogik, 1(2), 14-20. https://doi.org/10.20961/jdc.v1i2.17622

Putra, R. A., Kamil, M., \& Pramudia, J. R. (2017). Penerapan Metode Pembelajaran Mandiri Dalam Meningkatkan Hasil Belajar Peserta Didik. Jurnal Pendidikan Luar Sekolah, 13(1), 23-36.

Rusdiana, A., Kodir, A., \& Godjin, A. (2020). Risalah Ramadhan Mengharap Maghfirah 
Menuju Mardhatillah. Pustaka TRESNA BHAKTI Cibiru.

Sabri, A., Warmansyah, J., Amalina, A., \& Aswirna, P. (2020). Implementasi Pengintegrasian Keislaman Dalam Pengenalan Konsep Matematika Anak Usia Dini. 2020, 4(1), 23-30. https://doi.org/doi.org/10.15548/mej.v4i1.1240

Saihu, S. (2020). Konsep Pembaharuan Pendidikan Islam Menurut Fazlurrahman. Andragogi: Jurnal Pendidikan Islam Dan Manajemen Pendidikan Islam, 2(1), 82 95. https://doi.org/10.36671/andragogi.v2i1.76

Saleh, K., \& Jamil, N. (2020). Konstribusi Pembelajaran Aik Terhadap Pelaksanaan Ibadah Sholat Mahasiswa STKIP Muhammdyah Muaro Bungo. Jurnal Tunas Pendidikan, 3(1), 1-21. https://doi.org/10.52060/pgsd.v3i1.382

Septiani, A., \& Kejora, M. T. B. (2021). Tingkat Aktivitas Belajar Siswa pada Pembelajaran Online Pendidikan Agama Islam di Masa Pandemi Covid-19. Edukatif: Jurnal Ilmu Pendidikan, 3(5), 2594-2606.

Shofiyah, S. (2018). Prinsip-Prinsip Pengembangan Kurikulum dalam Upaya Meningkatkan Kualitas Pembelajaran. Edureligia; Jurnal Pendidikan Agama Islam, 2(2), 122-130. https://doi.org/10.33650/edureligia.v2i2.464

Suryani, L. (2007). Analisis Permasalahan Pendidikan Anak Usia Dini Dalam Masyarakat Indonesia. JIV, 2(1), 42-48. https://doi.org/10.21009/JIV.0201.6

Suryapermana, N., \& Imroatun. (2017). Dasar-dasar Ilmu Pendidikan. FTK Banten Press.

Tilaar, H. A. R. (2003). Kekuasaan Dan Pendidikan, Manajemen Pendidikan Nasional Dalam Pusaran Kekuasaan. Rineka Cipta.

Wantoro, A. (2019). Sistem Informasi Berbasis Web Untuk Pengelolaan Penerima Dana Zakat, Infaq Dan Sedekah. Jurnal Tekno Kompak, 13(2), 31. https://doi.org/10.33365/jtk.v13i2.338

Warmansyah, J. (2020). Program Intervensi Kembali Bersekolah Anak Usia Dini Masa Pandemi Covid-19. Jurnal Obsesi : Jurnal Pendidikan Anak Usia Dini, 5(1), 743. https://doi.org/10.31004/obsesi.v5i1.573

Warmansyah, J., \& Amalina, A. (2019). Pengaruh Permainan Konstruktif dan Kecerdasan Visual- Spasial Terhadap Kemampuan Matematika Awal Anak Usia Dini. Math Educa Journal, 3(1), 71-82. https://doi.org/10.15548/mej.v3i1.270

Zakariah, Askari, M., Afriani, V., \& Zakariah, M. (2020). Metodologi Penelitian Kualitatif, Kuantitatif, Action Research, Research and Development (RnD). Yayasan Pondok Pesantren Al Mawaddah Warrahmah Kolaka. 